\title{
Effects of Heat Treatment on Strength and Ductility of Rolled and Forged Aluminum 6063 Alloy
}

\author{
S. O. Adeosun ${ }^{1 *}$, S.A. Balogun ${ }^{1}$, O.I. Sekunowo ${ }^{1}$, M.A.Usman ${ }^{2}$ \\ ${ }^{1}$ Department of Metallurgical and Materials Engineering, ${ }^{2}$ Department of Chemical \\ Engineering University of Lagos, Akoka -Yaba, Lagos, Nigeria \\ *Corresponding Author: samsonoluropo@yahoo.com
}

\begin{abstract}
This work examines the effect of heat treatment on tensile strength and ductile responses of rolled and forged AA6063 aluminum alloy. Some cast samples were rolled while some were forged at ambient temperature $\left(32^{\circ} \mathrm{C}\right)$. The deformed samples were subjected to heat treatment processes. The tensile strengths of rolled (212 MPa) and forged (127 MPa) samples are enhanced at ambient temperature but with poor elongation responses. A combination of improved strength and elongation (127 MPa, 24\%) can be obtained in rolled sample when solution heat treatment (SHT) is applied after deformation and cooling in water. The forged sample when homogenized, solution treated and water quenched has elongation of about 24\% with improved strength of 137 MPa. These results were obtained because of the development of very fine AlFeSi texture in the matrix and along the grain boundaries.
\end{abstract}

Key words: aluminum alloy, forging, rolling, heat treatment, strength, ductility.

\section{INTRODUCTION}

The solution heat treatment (SHT) of heat treatable AA6063 aluminum alloy consists of solution treatment, quenching, and aging. During casting, however, the slow cooling rate of the alloy allows for the strengthening $\mathrm{Mg}_{2} \mathrm{Si}$ phase to precipitate out of solution and grow into large incoherent phases within the matrix. In the as-cast structure, the large, incoherent nature of the $\mathrm{Mg}_{2} \mathrm{Si}$ phase does little to increase the strength of the alloy .To obtain finely dispersed $\mathrm{Mg}_{2} \mathrm{Si}$, a solution heat treatment needs be conducted on the alloy. The process raises its temperature to near the melting point of the alloy but not high enough to initiate partial melting. At the 
solution temperature $\left(\sim 540^{\circ} \mathrm{C}\right.$ for $\mathrm{Al}-\mathrm{Si}-\mathrm{Mg}$ alloys $)$, the $\mathrm{Mg}_{2} \mathrm{Si}$ dissolves back into solution with the aluminum matrix. During quenching the alloy quickly cools from solution, locking the strengthening elements within the aluminum matrix. The alloy after quenching becomes meta-stable, where some silicon and magnesium crystals attempt to precipitate out as $\mathrm{Mg}_{2} \mathrm{Si}$ but cannot, since at room temperature, there is not enough energy for precipitation to occur. In aging, the part is raised to a high enough temperature to initiate precipitation of the $\mathrm{Mg}_{2} \mathrm{Si}$. During aging, the $\mathrm{Mg}_{2} \mathrm{Si}$ precipitates out as finely dispersed phases which anchor the matrix and impede deformation resulting in a significant increase in strength [1].

Totik et al investigated (2003) the effect of homogenization treatment conditions on cold deformation of aluminum alloys AA 2014 and AA 6063 by the torsion test. The alloys were homogenized at $320,370,420$ and $470^{\circ} \mathrm{C}$ for 8 hours [2]. Torsion tests were performed on as-cast and homogenized alloys at room temperature and at a strain rate of $2 \times 10^{-2} \mathrm{~s}^{-1}$. It was observed that the homogenization treatment affected the microstructure of the specimen tested. The secondary phases, which were large and distributed on grain boundaries before the homogenization treatment were small and spread through the grains after it. Compared to as-cast, the homogenization treatment improved the degree of cold deformation, depending on the kind of aluminum alloy and homogenization temperature.

It has been found that small amount of manganese in AA6063 aluminum alloy significantly helps in homogenizing and transforming the plate-like $\beta$-AlFeSi phase to more rounded $\alpha$-AlFeSi phase, which increases the ductility of the material $[3,4]$. Aluminum 6063 alloy was processed by upset forging and cold rolling at ambient temperatures and the tensile, ductile and hardness (HRN) properties of the samples were studied [5]. The UTS and HRN increased as the range of reduction from processing increases from 0 to 50 percent at room temperature. However, the ductility decreases correspondingly, thus indicating a low strain-hardening exponent.

The wear behavior of age-hardened AA6063 aluminum alloy under dry sliding conditions shows that artificial aging produces the harder structure that is attributable to acceleration of precipitation of $\mathrm{Mg}_{2} \mathrm{Si}$ and other phases such as $\mathrm{CuAl}_{2}$ and $\mathrm{AlFeSi}$. The microstructure was also altered by the aging treatment, as it was observed that the precipitates in the structure dispersed finely with increasing aging time [6]. The effect of precipitation on the tensile strength, yield strength, hardness, ductility and number of cycles required to fail the alloy at constant stress was investigated [7]. The variation in time and temperature improved the mechanical properties of the AA6063 aluminum alloy, whereas the ductility decreased. This study investigates the effect of homogenization, solution treatment, annealing, normalizing, quenching in water and aging on the mechanical properties of forged and rolled AA6063 aluminum alloy. 


\section{EXPERIMENTAL METHODOLOGY}

The ingot of AA6063 aluminum alloy used for this study was obtained from Aluminum Rolling Mills (ARM), Ota, Ogun State Nigeria and its chemical composition is given in Table 1 .

Table 1. Chemical Composition of AA6063 aluminum alloy.

\begin{tabular}{|l|l|l|l|l|l|l|l|l|l|l|l|}
\hline Element & $\mathrm{Mg}$ & $\mathrm{Si}$ & $\mathrm{Mn}$ & $\mathrm{Cu}$ & $\mathrm{Zn}$ & $\mathrm{Ti}$ & $\mathrm{Fe}$ & $\mathrm{Na}$ & $\mathrm{B}$ & $\mathrm{Sn}$ & $\mathrm{Al}$ \\
\hline $\begin{array}{c}\% \\
\text { Composition }\end{array}$ & 0.482 & 0.432 & 0.029 & 0.003 & 0.017 & 0.007 & 0.209 & 0.0003 & 0.001 & 0.0012 & 98.82 \\
\hline
\end{tabular}

The AA6063 aluminum alloy ingot was melted in a pit furnace and cast into $5.96 \mathrm{~mm}$ diameter x21 mm cylindrical samples using a metal mould. Fourteen cast samples were produced; seven were up-set forged in five passes using a pneumatic hammer of $56.31 \mathrm{kPa}$ and driven by a 4.5 -HP electric motor. The rest were rolled in fifteen passes using a two-high mill. One sample from each group was labeled as-cast without thermo mechanical processing. Forging and rolling were carried out on the samples to $60 \%$ cumulative thickness reduction at ambient temperature $\left(32^{\circ} \mathrm{C}\right)$. Six of the forged samples were homogenized at $515^{\circ} \mathrm{C}$ for 22 hours and five from each group were solution-treated at $525^{\circ} \mathrm{C}$ for 12 hours. After solutionizing the forged samples, one sample was normalized, one was quenched in water, one was annealed, and one was quenched in water and aged at $210^{\circ} \mathrm{C}$. The same treatment was given to solutionized rolled samples. Tensile test was carried out on heat treated forged and rolled samples and the control samples. The test samples were prepared in accordance with BS standard for non-proportional rectangular test pieces having corner radius of $1 \mathrm{~mm}$ and tensile tested on a table top Instron Electromechanical testing system, 3369 model at strain rate of $10 \mathrm{~mm} / \mathrm{min}$. The shape and dimensions of the test samples are shown in Figure 1.

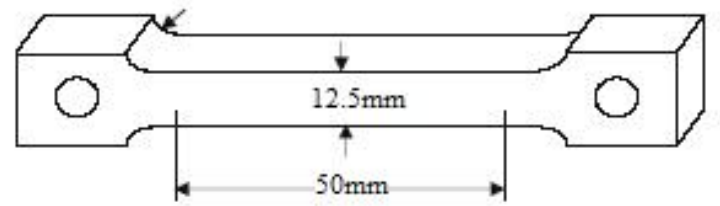

Figure 1: Tensile test specimen.

The microstructural states of control and coldworked specimens were investigated using standard metallographic procedures. Each sample was ground and polished before being etched in 2\% Sodium Hydroxide $(\mathrm{NaOH})$ solution for 20 seconds. Photographs of these structures were obtained using the digital metallurgical microscope at a magnification of X100 with $\alpha$-aluminum phase as white, $\mathrm{Mg}_{2} \mathrm{Si}$ crystal as dark and the AlFeSi crystal as brown. 


\section{RESULTS AND DISCUSSION}

The sample rolled at ambient temperature to a cumulative thickness reduction of $60 \%$ has superior UTS (212 MPa) to the forged sample (127 MPa) similarly deformed (see Figures 2-5 and Table 2).

Table 2. Ultimate Tensile Strength (UTS) and Elongation Characteristics of processed AA6063 Aluminum alloy.

\begin{tabular}{|l|l|l|l|l|}
\hline \multirow{2}{*}{ Thermal processing } & \multicolumn{2}{|c|}{ UTS (MPa) } & \multicolumn{2}{l|}{ Elongation } \\
\cline { 2 - 5 } & Forged & Rolled & Forged & Rolled \\
\hline Deformed at ambient temperature. & 126.98 & 212.4 & 2.49 & 6.1 \\
\hline Deformed and Homogenized. & 99.3 & 104.5 & 13 & 14 \\
\hline Deformed and homogenized, SHT and normalized. & 73.7 & 126.7 & 7.1 & 19 \\
\hline Deformed, homogenized, SHT and annealed. & 102.9 & 99.7 & 18 & 12 \\
\hline Deformed, homogenized, SHT and water quenched & 131.8 & 127.1 & 25 & 24 \\
\hline $\begin{array}{l}\text { Deformed, homogenized, SHT,water quenched and } \\
\text { aged }\end{array}$ & 107.76 & 93.8 & 17.2 & 9.8 \\
\hline As-cast & 114.8 & 114.8 & 10.6 & 10.6 \\
\hline
\end{tabular}

However, both samples show poor elongation responses as the values are far less (6.1\% and $2.5 \%$ respectively) than that obtained in the as-cast sample $(10.6 \%)$. In the as-rolled sample, the $\mathrm{Mg}_{2} \mathrm{Si}$ crystals are found at grain boundaries, matrix surface and in the rolling direction, with fine distribution, which serves as obstacles to the motion of dislocation during plastic deformation. 


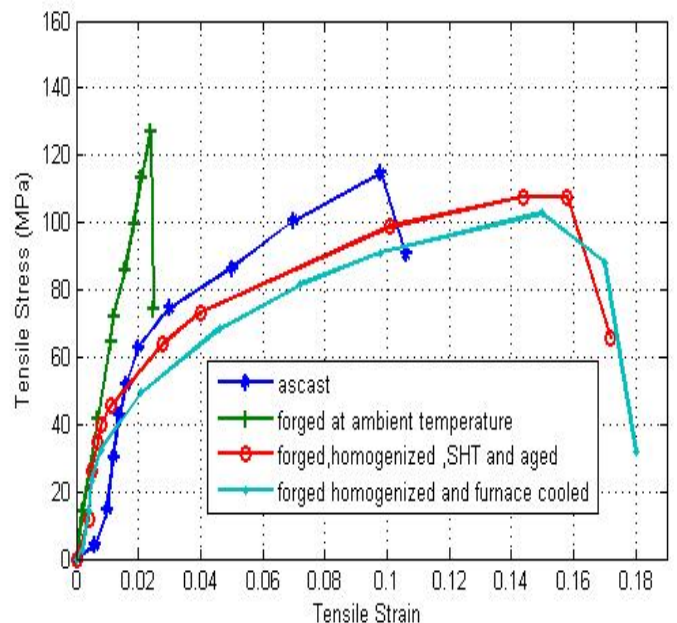

Figure 2 Tensile Stress against Tensile Strain for AA6063 Aluminum

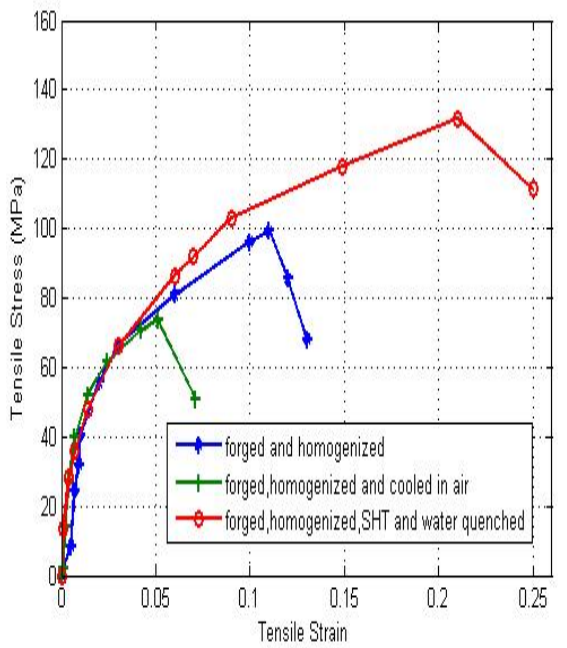

Figure 3 Tensile Stress against Tensile Strain for Forged AA6063 Aluminum 

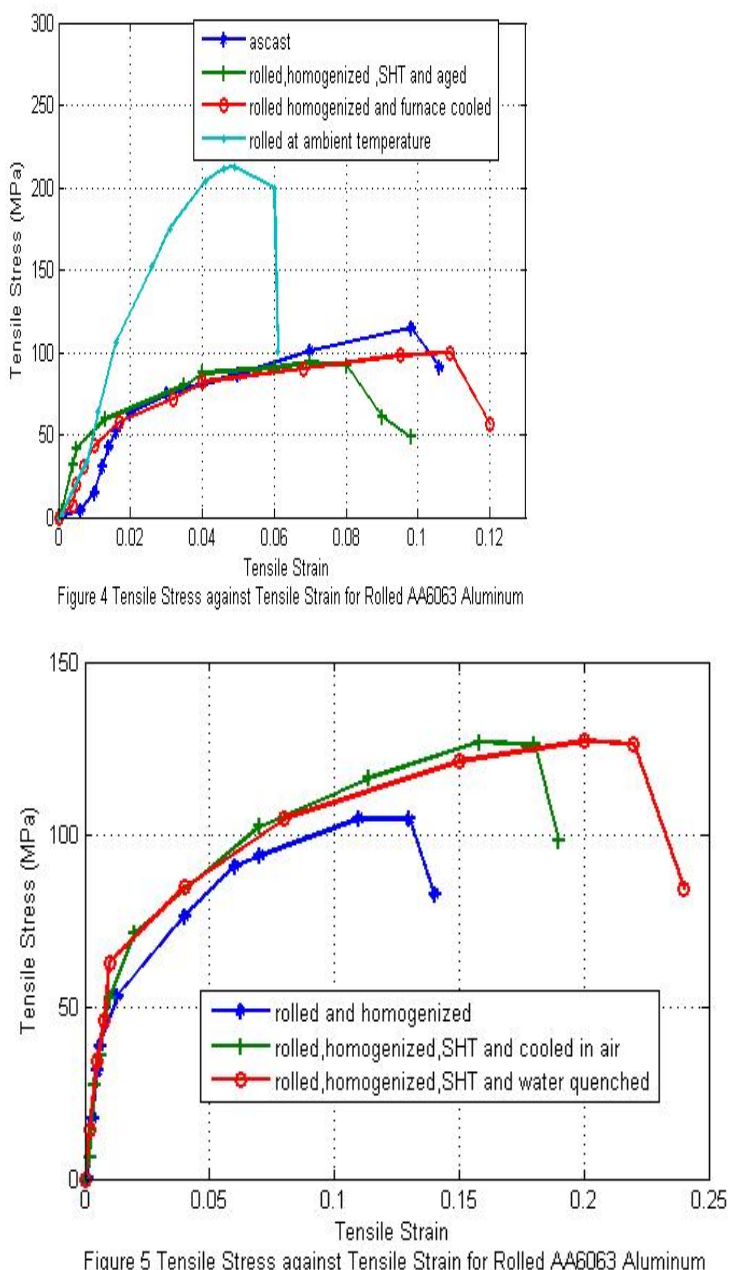

Other intermetallic crystals are fine and of smaller volume fraction (see Plate 2a). These features promote strength while sacrificing ductility. In the as-forged sample, $\mathrm{Mg}_{2} \mathrm{Si}$ crystals which are predominantly needle-like in shape are scattered over the matrix surface. The volume of the AlFeSi phase precipitated exceeds that of $\mathrm{Mg}_{2} \mathrm{Si}$ that has some of its crystals diffused into the matrix consequent upon the applied forging load (see Plate 1a).

Homogenizing the forged sample at $515^{\circ} \mathrm{C}$ and even normalizing after treatment at $525^{\circ} \mathrm{C}$ does not promote the precipitation of strength enhancing phase over that observed in the as-cast structure. The percent elongation at these heat treatment procedures however, increases significantly over the as-cast. There is a decline in strength of forged sample whereas the property improved in the rolled sample. The volume of $\mathrm{Mg}_{2} \mathrm{Si}$ and other intermetallics precipitated decreased with $\mathrm{Mg}_{2} \mathrm{Si}$ crystal distribution in similar pattern to solution treated sample (see Plate 1b). During normalization of homogenized rolled sample, $\mathrm{Mg}_{2} \mathrm{Si}$ and other intermetallic crystals are precipitated over the homogenized sample. This gave rise to strength and 
elongation increases (see Plate 1c). Normalizing the homogenized forged sample did not improve the precipitation and distribution of $\mathrm{Mg}_{2} \mathrm{Si}$. There was incoherent clustering of $\mathrm{Mg}_{2} \mathrm{Si}$ crystals in the matrix resulting in a further reduction in strength (see Plate 1c).

Subjecting deformed samples after homogenizing at $515^{\circ} \mathrm{C}$ to water quenching at $525^{\circ} \mathrm{C}$ resulted in strength evolution similar to as-cast but with elongation that is twice $(25 \%)$ as much as the as-cast (11\%). A striking observation here is that the strength and elongation of forged and rolled samples are quite similar. If the sample is quenched in water instead of air cooling, the volume of precipitated $\mathrm{Mg}_{2} \mathrm{Si}$ in rolled sample does not significantly increase. Rather, there is an increase in volume fraction of other intermetallics giving rise to enhanced ductility (see Plate 1d). There is an increase in $\mathrm{Mg}_{2} \mathrm{Si}$ precipitated in the matrix at the grain boundaries and more of the other intermetallics are produced to enhance elongation response of the sample (see Plate 1b).

Annealing the sample instead of quenching in water does not increase the volume of precipitated $\mathrm{Mg}_{2} \mathrm{Si}$ and other intermetallics (see Plate 1d).

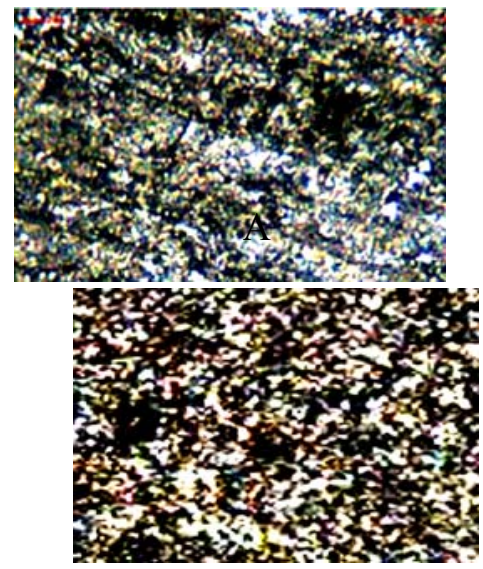

a

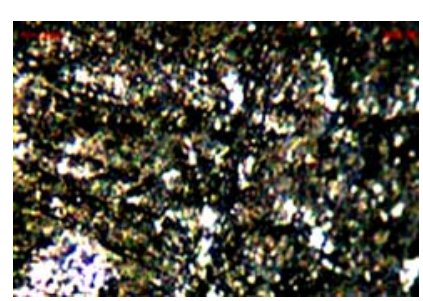

b $\mathrm{c}$ 


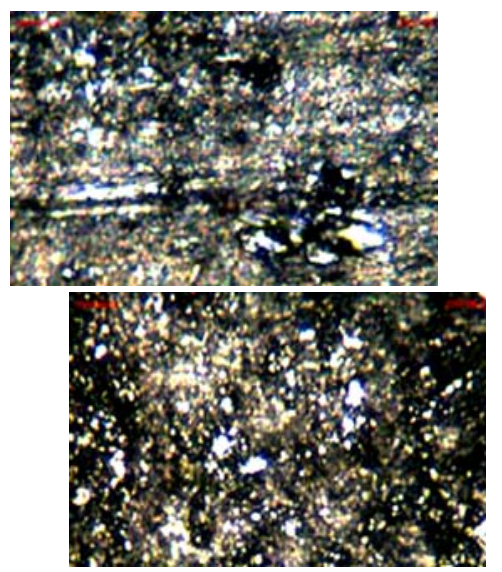

d

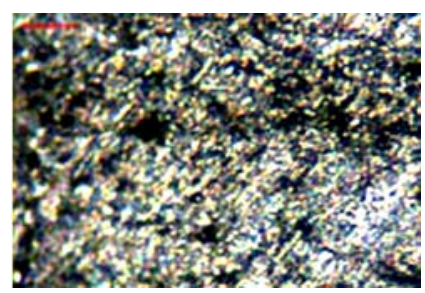

e

f

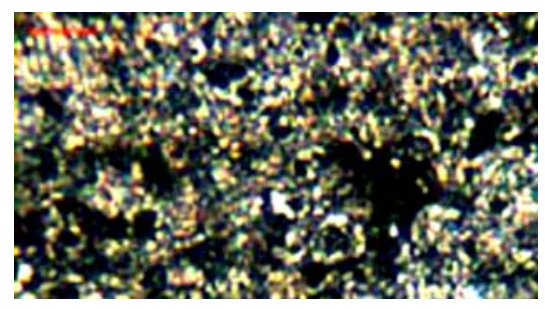

g

Plate 1. Structural morphology of rolled samples (a) deformed at ambient (b) deformed and homogenized at $515^{\circ} \mathrm{C}$ (c) deformed, homogenized at $515^{\circ} \mathrm{C}$ and normalized at $525^{\circ} \mathrm{C}$ (d) deformed, homogenized at $515^{\circ} \mathrm{C}$ and water quenched at $525^{\circ} \mathrm{C}$ (e) deformed, homogenized at $515^{\circ} \mathrm{C}$ and annealed at $525^{\circ} \mathrm{C}$ (f) deformed, homogenized at $515^{\circ} \mathrm{C}$, quenched and aged at $210^{\circ} \mathrm{C}(\mathrm{g})$ as-cast.
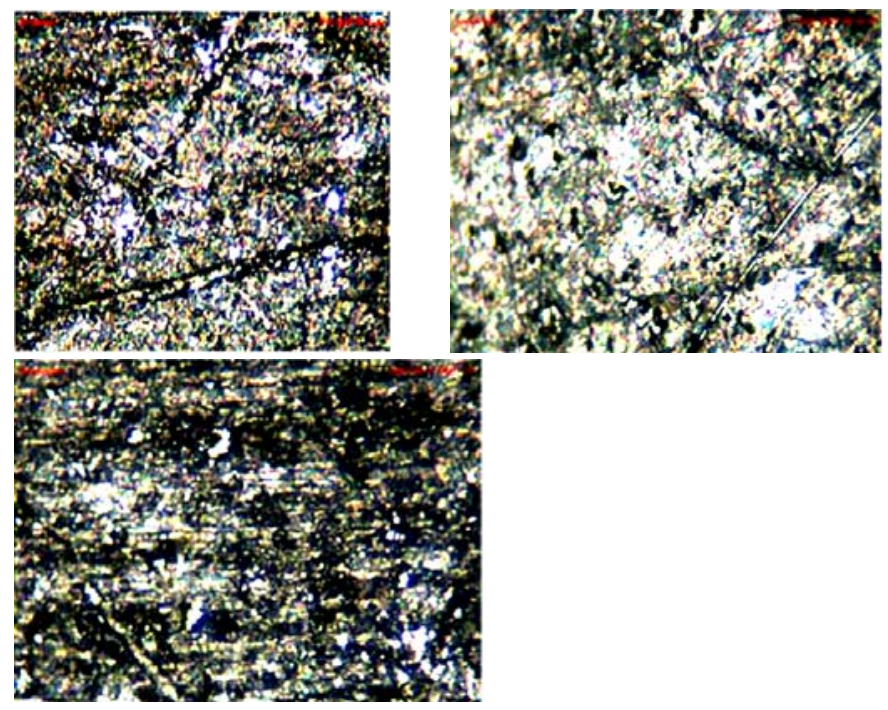
a

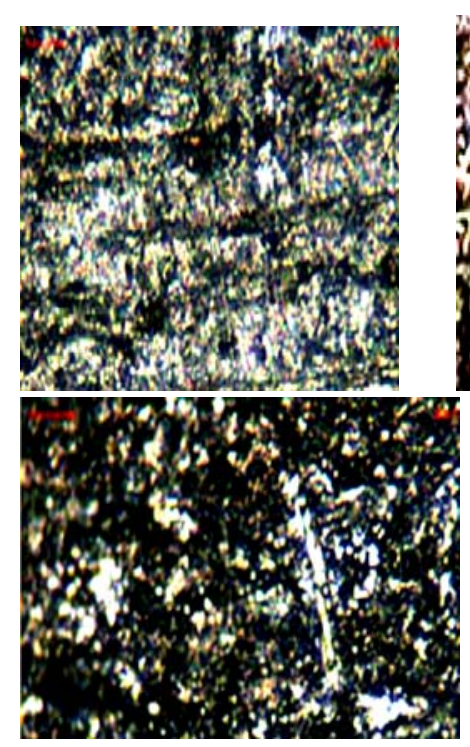

d b

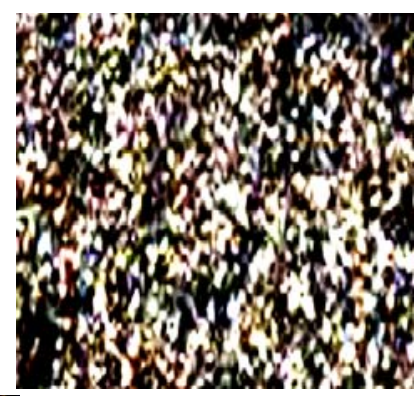

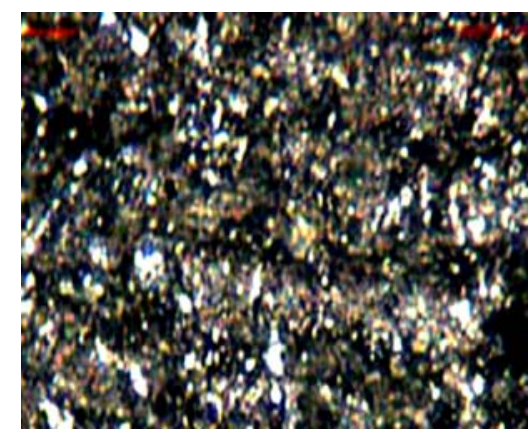

$\mathrm{g}$

Plate 2. Structural morphology of forged samples (a) deformed at ambient (b) deformed and homogenized at $515^{\circ} \mathrm{C}$ (c) deformed, homogenized at $515^{\circ} \mathrm{C}$ and normalized at $525^{\circ} \mathrm{C}$ (d) deformed, homogenized at $515^{\circ} \mathrm{C}$ and water quenched at $525^{\circ} \mathrm{C}$ (e) deformed, homogenized at $515^{\circ} \mathrm{C}$ and annealed at $525^{\circ} \mathrm{C}$ (f) deformed, homogenized at $515^{\circ} \mathrm{C}$, quenched and aged at $210^{\circ} \mathrm{C}(\mathrm{g})$ as-cast.

Annealing forged sample after homogenization does not produce significant improvement in strength (103 MPa) over the homogenized sample (99MPa). But the elongation improves (18\% as against $13 \%)$ due to the increased precipitation of other intermetallics (see Plate 2e). Annealing after SHT at $525^{\circ} \mathrm{C}$, water quenching and ageing at $210^{\circ} \mathrm{C}$ and homogenization treatments did not enhance the tensile strength of both forged and rolled samples. However ductility improved. Ageing the quench sample at $210^{\circ} \mathrm{C}$ does not improve the precipitation of the strengthening phase (see Plate $2 \mathrm{f}$ ). At $60 \%$ cumulative reduction and in the range of heat treatment considered, rolled samples allowed for the evolution of strengthening precipitates, permit increase 
in crystal-size and generate mobile dislocations for superior ductility over the as-cast structure. The precipitation of other intermetallics is similarly affected (see Plate 1f). The as-cast structure contains fine equiaxed crystals of the phases in roughly equal amounts in the matrix (see Plate $2 \mathrm{~g}$ ). The $\mathrm{Mg}_{2} \mathrm{Si}$ crystals are visible at the grain boundaries.

The peak ductility of forged (25\%) and rolled (24\%) samples obtained after deformation, homogenization, solution heat treatment and water quenched processes in this study are superior to the results obtained for the same alloy by the works of Balogun et al (2007), Siddiqui et al (2000) and Al-Marahleh (2006) [5,7,8]. The reason for this improve elongation can be attributed to the transformation of platelike $\beta$-AlFeSi phase to round $\alpha$ - AlFeSi phase which increases the ductility of the material [3,4]. This was ensured in the study of Zajai et al (1993) [3] by the addition of small amount of manganese. However, there is similarity in the elongation of cast sample homogenized at $580^{\circ} \mathrm{C}$ for 6 hours and followed by extrusion $(28 \%)$ in the study by Al-Marahleh (2006) [8] with the results obtained in this study.

\section{CONCLUSION}

The study has shown that the ultimate tensile strength (UTS) and ductility of forged aluminum 6063 alloy can be improved after deformation processing by quenching in water after solution treatment at $525^{\circ} \mathrm{C}$. The elongation of $25 \%$ at ultimate strength of $132 \mathrm{MPa}$ is superior to the as-forged condition (2.5\%). The results are consequent upon the increase in fineness of the texture of AlFeSi and its precipitation at the grain boundaries. The incoherent precipitates of $\mathrm{Mg}_{2} \mathrm{Si}$ enhance the ductility of the sample as dislocation movements are permitted.

In the rolled alloy, superior strength and high ductility are conferred after rolling by solution treatment followed by normalizing or quenching in water. However, if it is desired to produce a material possessing high strength with little ductility, the alloy may be cold rolled without any other treatments. If it is desired to have texture changes in the sample microstructure, solution treatment of rolled sample followed by normalizing can be applied to improve the as-cast texture, which shows fine crystals of well distributed phases. Deformation (rolling) combined with thermal treatment such as homogenization, SHT quenching in water and or ageing will produce large volume of AlFeSi crystals in $\alpha$-Aluminum matrix for enhanced ductility.

\section{REFERENCES}


1. Jay Keist, (2005): Development of fludized bed system for the heat treatment of aluminum alloys, Journal of materials, 2005, 36.

2. Y. Totik*, R. Sadeler, I. Kaymaz, M. Gavgali ( 2003) :The effect of homogenisation treatment on cold deformations of AA 2014 and AA 6063 alloys, Journal of Materials Processing Technology 147 (2004) 60-64, October 2003.

3. S. Zajac, B. Hutchinson, A. Johanson, L.O. Gullman, R. Lagneborg (1993): Microstructure control and extrudability of Al-Mg-Si alloys, microalloyed with manganese, J. Physique 3 (7) (1993) 251-254.

4. I. Musulin, O.C. Celliers (1990): Role of manganese in 6063 alloy and effect of quench sensitivity in 6063, in: Proceedings of the TMS Annual Meeting on Light Metal, Vol. 119, Minerals Metal and Material Society (TMS), Warrendle, PA, 1990, pp. 951-954.

5. Sanmbo A. Balogun, David E. Ezesobor, Samson O. Adeosun (2007): Effect of deformation processing on the mechanical properties of Aluminum alloy 6063, Metallurgical and Material Transactions A, Volume 38, Pg 1570-1574, July 2007.

6. M. Gavgali, Y. Totik, R. Sadeler ( 2003) :The effect of Artificial Aging on wear properties of AA6063 Alloy, Materials Letters 57 (2003) 3713- 3721

7. Rafiq A. Siddiqui, Hussein A. Abdullah, Khamis R. Al-Belushi ( 2000) :Influence of aging parameters on the mechanical properties of 6063 aluminum alloy, Journal of Materials Processing Technology 102 (2000) $234 \pm 240$.

8. G. Al-Marahleh (2006): "Effect of heat treatment on the distribution and volume fraction of $\mathrm{Mg}_{2} \mathrm{Si}$ in Structural Aluminum Alloy 6063." Journal of Metal Sciences and Heat treatment Vol.48, Nos 5-6, Pg. 17-21. 